\title{
Parents' Beliefs about Children's Math Development and Children's Participation in Math Activities
}

\author{
Susan Sonnenschein, ${ }^{1}$ Claudia Galindo, ${ }^{2}$ Shari R. Metzger, ${ }^{1}$ Joy A. Thompson, ${ }^{1}$ \\ Hui Chih Huang, ${ }^{2}$ and Heather Lewis ${ }^{1}$ \\ ${ }^{1}$ Department of Psychology, University of Maryland, Baltimore County, Baltimore, MD 21250, USA \\ ${ }^{2}$ The Language, Literacy, and Culture Program, University of Maryland, Baltimore County, Baltimore, MD 21250, USA
}

Correspondence should be addressed to Susan Sonnenschein, sonnensc@umbc.edu

Received 12 May 2012; Revised 31 August 2012; Accepted 6 September 2012

Academic Editor: Helga Krinzinger

Copyright (C) 2012 Susan Sonnenschein et al. This is an open access article distributed under the Creative Commons Attribution License, which permits unrestricted use, distribution, and reproduction in any medium, provided the original work is properly cited.

\begin{abstract}
This study explored associations between parents' beliefs about children's development and children's reported math activities at home. Seventy-three parents were interviewed about the frequency of their children's participation in a broad array of math activities, the importance of children doing math activities at home, how children learn math, parents' role in their children's math learning, and parents' own math skills. Although the sample consisted of African Americans, Chinese, Latino, and Caucasian parents in the United States, the majority were Chinese or Caucasian. Several important findings emerged from this study. Parents' beliefs about math development and their role in fostering it were significantly related to children's math activities. There was important variability and relatively limited participation of children in math activities at home. There were age-related differences in children's engagement in math activities. Chinese and Caucasian parents showed somewhat similar beliefs about how children developed math. Although further research is needed to confirm the findings with a larger sample and to include measures of children's math competencies, these findings are an important step for developing home-based interventions to facilitate children's math skills.
\end{abstract}

\section{Introduction}

Many children in the United States do not exhibit adequate math skills [1]. On average, US children earn significantly lower math scores on international assessments such as PISA and TIMSS than children from other industrialized nations $[2,3]$. The importance of children's early math skills is well documented. Early math skills continue to have longlasting effects as children progress through school [1, 47]. And math skills have been recognized as important for individual upward mobility and advancing U.S. standing in the global market [1]. Given that there is significant variability in the math skills with which children enter school [4] and that early math skills predict later ones [6], it is critical to identify mechanisms to improve young children's math understanding. One important but relatively understudied mechanism to improve children's math skills during preschool and the early school years is the home-math environment.
Young children's home-based math experiences, including playing games and engaging in everyday math activities, positively predict their math skills ([8-12]; see also [13], for further discussion of the relation between home learning environment and children's academic development). For example, LeFevre and colleagues $[10,11]$ demonstrated that the frequency with which children in kindergarten through second grade engaged in home-based math activities such as playing board and card games, cooking, and shopping positively predicted their scores on measures of math knowledge and fluency. Ramani and Siegler [14] found that playing board games at home positively predicted children's scores on a measure of number sense.

Although the frequency of engagement in home-based math activities predicts children's math skills, a nontrivial percentage of children reportedly do not engage in much, if any, math activities at home [14, 15]. Ramani and Siegler [14], for instance, found that $20 \%$ of middle-income 
children and $53 \%$ of low-income children did not report playing any math games at home. Tudge and Doucet [15] found $60 \%$ of the low- and middle-income preschoolers in their study had no involvement with math-related activities at home. In order to understand the variability in children's engagement in math activities, it is necessary to understand factors that predict such engagement.

This study investigates the relations between parental beliefs about how to foster young children's math development and the frequency of children's reported math activities at home. We provide descriptive information of parental beliefs about the importance of children doing math activities at home, beliefs about how children learn, parents' role in their children's math learning, and parents' own math skills as well as the types of math activities children do at home. We also document similarities and differences in parents' beliefs and children's math activities for younger (prekindergarten and kindergarten) and older children (early elementary school), and for Chinese and Caucasian parents. We then examine the association between the frequency of children's participation in math activities and parents' beliefs.

Our conceptual framework reflects ecological and sociocultural theories, which emphasize the importance of considering the individual and overlapping contexts within which children's development occurs (e.g., $[16,17]$ ), to understand the importance of the home-environment for math development.

A key aspect that influences the context of children's lives according to Super and Harkness [18] is parental beliefs. Parents have specific beliefs about child development that predict the experiences they make available to their children [19] which, in turn, predict children's math development (see also [20-22]). Parents also have ideas about their role in their children's development $[19,23,24]$. These ideas or beliefs reflect parents' cultural heritage and experiences and predict their behavior and practices [21, 25, 26]. Many current theories of children's development emphasize the importance of parental beliefs $[27,28]$; however, very little research, with the exception of the following two studies, has investigated the beliefs that parents have about their children's math development and how such beliefs relate to children's engagement in math activities at home.

Simpkins et al. [29] found that parents' socialization of their children's math behavior in elementary school (2nd5 th grades) was related to their children's engagement in out of school activities in math, science, and computer usage. Skwarchuk [12] demonstrated that parents' prior experiences with math were positively related to the frequency of their preschoolers' math activities and math knowledge. Prior experiences were assessed with two questions asking parents to rate how good at math they were in school and whether they found math enjoyable.

An important criticism of Skwarchuk's [12] study is the measure of math activity involved an intervention component; it was not a measure of normative (or daily/routine) math activity because parents were given a bag of math materials and were told to play math-related activities for 1015 minutes each day. We add to findings from these studies by examining the confluence of different indicators of parental beliefs.

In contrast to research on children's math development, research has examined the relation between children's homeenvironment and their reading development. Parents who emphasize the importance of engaging their young children's interest in reading have children who choose to read more frequently which, in turn, positively predicts their reading development [30].

The Early Childhood Project [23] was a longitudinal investigation of literacy development with children from diverse income and ethnic/racial backgrounds in prekindergarten through third grade. It provides an impetus for how parents' beliefs about children' math development were assessed in this study. Parents in the Early Childhood Project were asked about the best way to foster their young children's literacy development. Parents' responses were coded for three possible orientations towards literacy development: engaging children's interest/making reading entertaining or enjoyable for the child, inculcating skills, and using daily living activities. Parents' orientation towards engaging young children's interest in reading was related to the types of activities in which children engaged in prekindergarten through third grade. An orientation towards engaging children's interest was also positively related to early literacy and reading competencies. In contrast, an orientation focused on skills inculcation was either not related or negatively related to children's literacy development (see also [31]). Although it seems reasonable to assume that findings of the relation between parents' beliefs and children's reading development will extend to children's math development, it is possible that home environments could have a differential impact on the two domains, given that reading and math require different skill sets.

Findings from the Early Literacy Project also showed the changing nature of children's home-based activities as they get older and become better readers [23]. Research also shows that parents' beliefs assessed when children are in preschool continue to predict their development in elementary school $[13,23]$. However, to our knowledge, no research on math development has specifically investigated differences in parents' beliefs about their children's learning or their role in such learning for different age groups of children. This study compares similarities and differences in parents' beliefs and children's activities for younger and older age groups of children.

Another important issue when studying the homelearning environment of children is to take into account the interaction between cultural manifestations and responses to the larger social structure. As Super and Harkness [32] argue, the home-learning environment that parents create for their children includes both culturally defined and transmitted messages. Harkness and Super [33] argue that culture impacts family functioning and child development at the proximal and distal levels through 3 mechanisms: physical and social settings (structure and organization of the home plus individuals who interact with child), culturally specific childcare customs (common parenting behaviors that are well integrated into the larger structure), and ethnotheories 
of parenting (specific beliefs about significance and role, expectations about behaviors and development, and nature and needs of children). These three factors, physical and social settings, culturally specific child care customs, and ethnotheories of parenting comprise the developmental niche [18]. Individual differences in the developmental niche reflect differences in ethnic/cultural background and income and are related to differences in children's development [34].

Particularly relevant for this study are the cultural differences between Asian (Chinese) and Western (Caucasian) parents' beliefs and socialization practices. Such differences may account, at least in part, for differences in children's developmental outcomes. It is a well-documented finding that Chinese children display higher math skills from the outset of schooling than Caucasian children (e.g., $[35,36]$ ). Asian parents consider schooling one of the most important responsibilities of parents, strongly believe that without a solid education a person cannot be successful in life [37], and clearly articulate their educational expectations [38]. Such a strong emphasis on education may not be found among Western parents.

Another important belief commonly found among Asian parents is related to the relation between academic success/learning and children's ability/effort. Asian and Asian American parents consider hard work and effort as the key for academic success [39]. In contrast, Caucasian parents consider ability as a very important determinant of academic success, which implies a more deterministic view of academic success [40]. These beliefs have important consequences for Asian parents' socialization practices. This study compares and contrasts Chinese and Caucasian parents' socialization beliefs and practices.

In short, the present study investigates relations between parents' beliefs about how to facilitate their children's math development and the frequency of children's math activities at home. We considered four sets of parental beliefs: the importance of children doing math activities at home, how children learn math, parents' role in their children's math learning, and parents' own math skills. How children learn math included three possible orientations: engaging child's interest, inculcating skills, and using daily living activities. Note that we assess parents' beliefs in a more comprehensive manner than has been done in the limited prior research and with a more ethnically/racially diverse sample. We also assess relations among parents' beliefs and children's involvement in math activities.

\section{Method}

2.1. Participants. Families were recruited from local schools and preschools, Chinese schools and churches, and community centers in a large city in the Middle Atlantic section of the United States. Data were collected in two waves, during the spring and summer of 2010 (Wave 1) and during the fall of 2011 and spring of 2012 (Wave 2). Data from the first wave included families from four ethnic/racial groups, data from Wave 2 were collected to allow comparisons between Chinese and Caucasian families. On average, participants in both waves of data were comparable in their demographic characteristics except for their average levels of education. As expected, Wave 2 participants were significantly more educated $($ Mean $=5.50, \mathrm{SD}=0.71$; college completion/graduate school) than Wave 1 participants (Mean $=4.30, \mathrm{SD}=$ 1.89; associate degree), $F(1,52)=11.68, p=.001$, partial eta squared $=.183$. Accordingly, data from both waves of participants were combined in all analyses.

Table 1 shows demographic characteristics of the 73 participants in this study. All participants were mothers of children in prekindergarten through fourth grade; the majority of the children were in prekindergarten through second grade. About $68 \%$ of the children lived in dual parent households. Participants came from four racial/ethnic groups: African American, Chinese, Latino, and Caucasian. The mean age of the participants was 36.58 years $(\mathrm{SD}=$ 8.06).

All of the Chinese parents and $80 \%$ of the Latinos in our sample were first generation (foreign-born) immigrants. Chinese and Latino immigrants had lived in the Unites States for an average of 9.01 years $(S D=5.39)$. Consistent with U.S. population statistics, Chinese parents were the most educated; about $93 \%$ completed at least college in contrast to $44 \%$ of African American, $62 \%$ of Caucasian, and $20 \%$ of Latino parents.

2.2. Task and Procedure. The Parents' Conceptions of Math Development (PCMD) questionnaire was used to assess parents' beliefs and reported frequency of children's engagement in math activities. It included open-ended questions and rating scales about parents' metacognitions about math, the importance of home-based math engagement for children, parents' views of how children learn math, parents' roles in such learning, parents as role models of math engagement, and the frequency of children's math engagement across a broad base of theoretically-relevant math activities. Versions of the questionnaire were available in English, Mandarin, and Spanish. Mandarin and Spanish questionnaires were first prepared in English, and then translated and back-translated to ensure linguistic validity.

A trained graduate or advanced undergraduate research assistant administered the questionnaire in the parent's preferred language. Completion of the questionnaire took about 30-40 minutes. The research assistant took notes and audio-taped the interviews.

Tapes were transcribed and then reviewed by the interviewer and another member of the research team. Questionnaires conducted in Mandarin or Spanish were transcribed in that language, translated into English, and then back-translated by a third assistant. The two versions were compared and any inconsistencies were discussed among the transcriber and translators.

Coding was based on the written transcript with the oral tapes and field notes consulted as needed.

2.3. Key Variables. The key variables of interest in this study were parents' beliefs and frequency of children's math activities. 
TABLE 1: Demographic characteristics of sample.

\begin{tabular}{|c|c|c|c|c|c|}
\hline & $\begin{array}{l}\text { Overall } \\
N=73\end{array}$ & $\begin{array}{l}\text { Chinese } \\
N=28\end{array}$ & $\begin{array}{c}\text { Caucasian } \\
N=26\end{array}$ & $\begin{array}{c}\text { African American } \\
\qquad N=9\end{array}$ & $\begin{array}{l}\text { Latinos } \\
N=10\end{array}$ \\
\hline Boys (\%) & 56.2 & 60.7 & 65.4 & 33.3 & 40 \\
\hline Mean age (SD) & $6.12(1.60)$ & $6.26(1.84)$ & $5.83(1.83)$ & $6.10(1.28)$ & $6.24(1.62)$ \\
\hline \multicolumn{6}{|l|}{ Children's grade (\%) } \\
\hline Prekindergarten & 23.3 & 21.4 & 26.9 & 22.2 & 20 \\
\hline Kindergarten & 31.5 & 42.9 & 19.2 & 33.3 & 30 \\
\hline First grade & 26.0 & 17.9 & 38.5 & 22.2 & 20 \\
\hline Second grade & 6.8 & 3.6 & 11.5 & 11.1 & 0 \\
\hline Third grade & 11.0 & 14.3 & 0 & 11.1 & 30 \\
\hline Fourth grade & 1.4 & 0 & 3.8 & 0 & 0 \\
\hline Two-parent homes (\%)* & 68.1 & 85.7 & 61.5 & 33.3 & 66.7 \\
\hline $\begin{array}{l}\text { Number of other children in } \\
\text { home }\end{array}$ & $1.07(0.93)$ & $0.75(0.65)$ & $1.27(0.96)$ & $1.44(1.51)$ & $1.10(0.74)$ \\
\hline \multicolumn{6}{|l|}{ Mean $(S D)$} \\
\hline $0 \%$ & 27.4 & 35.7 & 19.2 & 33.3 & 20 \\
\hline 1 & 49.3 & 53.6 & 50 & 33.3 & 50 \\
\hline 2 & $13.7 \%$ & 10.7 & 15.4 & 0 & 30 \\
\hline 3 & 8.2 & 0 & 15.4 & 22.2 & 0 \\
\hline 4 & 1.4 & 0 & 0 & 11.1 & 0 \\
\hline Child fluent in English (\%) & 56.5 & 44.4 & 100 & 100 & 50 \\
\hline Parent education & $4.55(1.72)$ & $5.54(0.74)$ & $4.54(1.68)$ & $3.78(1.92)$ & $2.50(1.58)$ \\
\hline \multicolumn{6}{|l|}{ Mean level (SD) } \\
\hline Less than HS (\%) & 8.2 & 0 & 11.5 & 0 & 30 \\
\hline High school & 12.3 & 0 & 3.8 & 44.4 & 40 \\
\hline Some college & 4.1 & 3.6 & 3.8 & 11.1 & 0 \\
\hline Associate & 9.6 & 3.6 & 19.2 & 0 & 10 \\
\hline Bachelor & 23.3 & 28.6 & 23.1 & 11.1 & 20 \\
\hline Postgraduate & 42.5 & 64.3 & 38.5 & 33.3 & 0 \\
\hline Parent U.S. born (\%) & 49.3 & 0 & 96.2 & 100 & 20 \\
\hline
\end{tabular}

Note. ${ }^{*}$ One Hispanic parent did not provide data for this question.

2.3.1. Parents' Beliefs. Four types of beliefs were assessed: importance of children doing math activities at home, beliefs about how children learn, parents' role in their children's math learning, and parents' own math skills.

Importance of Children Doing Math Activities at Home. Parents were asked, "How important is it that your child does math activities at home?" Responses could range from 1 (not very) to 5 (very important).

Beliefs about How Children Learn Math. Parents were asked, "What is the best way to help your child learn math?" Responses to the open-ended question were reliably coded as focusing on entertaining or engaging the child ("to play math games with him" or "do an activity that will hold her attention..."), developing skills ("count numbers with him" or "sitting down and showing her the numbers on paper"), or using daily living activities ("taking advantage of everyday activities that incorporate math in them" or "counting cars on the road when we drive to the store"). Each of these beliefs are binary variables $(1=$ it was mentioned during the conversation, $0=$ was not mentioned). These beliefs were not mutually exclusive; parents' responses could include more than one focus. Reliability of coding was based on two raters independently coding 16 of the interviews. Kappas ranged from .875 to 1.00 .

In reviewing the transcripts of the interviews, it became apparent that parents' discussion of their beliefs about how children learn extended beyond their response to a specific question. Therefore, we complemented response to the previous question with information from the entire transcript. We call responses that emerged from review of the entire transcript "themes" to contrast them with responses to specific questions. We coded a theme of how children learn math with the same coding scheme (described in prior paragraph) as for the specific question. All responses were reviewed by two coders. These coders had established adequate reliability for the themes using a subset of 20 interviews. Kappas for each of the orientation themes were 1.00. Because the themed responses were based on more 
information than the response to a specific question, and because themed responses were correlated with responses to a specific question (.33 skills, .53 daily living, .58 engagement), the analyses presented in the paper include only the themed responses.

Parents' Role in Their Children's Math Learning. There were three separate roles parents could take: they serve as role models of math engagement, they provide children with artifacts, and they provide instructions. These roles were not mutually exclusive; parents could play more than one role.

(1) Serve as role model of math engagement. Parents were asked to rate on a 4 -point scale $(1=$ never/almost never through 4 = everyday/almost every day) "How often does your child see you engage in math activities?"

(2) Provide artifacts. Responses from the entire transcript were reviewed to identify whether parents discussed providing artifacts for their children as a part of the way they socialized their children's math skills. Two examples of remarks consistent with this role include, "We got him a math book," and "She has a counting book." A parent received a code of 1 if she mentioned the theme and 0 if she did not. The kappa for this theme was 1.00 .

(3) Active involvement in children's math learning. Parents were asked to rate, "How important is it that you help your child with math?" Responses could range from 1 (not very) to 5 (very).

Parents' Own Math Skills. Parents were asked, "How good at math are you?" and "How much do you enjoy math?". Ratings on each question ranged from 1 (not good at all) to 5 (very good).

2.3.2. Frequency of Children's Math Activities. The frequency of children's math activities was assessed using two indicators, overall math activity and a composite indicator based on specific math activities.

Overall Math Activity. Parents were asked about their children's overall math activity, "How often does your child engage in math activities?" Ratings were 0 (never, almost never), 1 (less than once a week), 2 (once a week to several times a week), and 3 (everyday/almost every day).

Specific Math Activities. Parents were asked to rate the frequency of children's participation in a broad-range of 27 specific math-relevant activities (e.g., counting, playing board games, and playing jigsaw puzzles). We used the same rating scale (from 0 to 3 ) as with the previous indicator of overall math activity. Scores on these specific math items were averaged. The items comprising the specific math activities composite showed good internal consistency (Cronbach's alpha of .80).
2.3.3. Covariates. Mothers' educational level, a proxy for socioeconomic status, was included as a control variable in the statistical analyses. Educational levels were coded into six categories: $1=$ less than high school degree, $2=$ high school graduate, $3=$ some college, vocational or technical school, $4=$ associate degree, $5=$ bachelor degree, and $6=$ postgraduate degree. Although income and maternal education are separate factors, they are highly related [41]. In fact, several researchers note that much of the differences in children's educational outcomes or factors related to their education are predicted by maternal education rather than income. For example, Suizzo and Stapleton [42], using a large U.S. nationally representative sample, found that maternal education was the strongest predictor of parental involvement. Income was not a significant predictor when maternal education was included as a predictor (see also [43], for further analysis of the role of income and education).

The data in this study revealed systematic group-based differences in parents' education. Chinese parents had significantly higher educational levels than Caucasians who, in turn, had significantly higher educational levels than Latinos, $F(1,71)=12.48, p=.001$. African Americans' educational levels fell between Caucasians and Latinos but did not differ significantly from either group $(p>.10)$. There were no significant differences in the educational levels between parents of younger and older children, $F(1,71)=$ 1.56, $p=.216$. Preliminary correlational analyses found that parents' educational level was significantly related to several parental beliefs: importance of assisting child with math activities, $r(72)=.29, p=.013$, and children learn math through a skills-based focus at home, $r(72)=-.24$, $p=.04$. There also was a borderline effect for parents' selfreported math skills, $r(72)=.21, p=.069$.

\section{Results}

This section begins with unadjusted descriptive information (no controls for mother's educational level) of parents' beliefs about their children's math development for the entire sample. We then compare beliefs of parents of younger (prekindergarten, kindergarten) and older children (first grade and older). We also present ethnic/racial comparisons between the Chinese and Caucasian parents; comparisons for African Americans and Latinos are not included because of their relatively small sample size. We next present information about children's reported math activities following the same strategy as we did for the analysis of parental beliefs. Finally, we analyze relations between parents' beliefs and the frequency of children's math activities for the entire sample. We control for mother's educational level in all analyses (correlations, analysis of covariance, and regressions) except for descriptive information.

\subsection{Parents' Beliefs about Children's Math Development}

3.1.1. Importance of Children Doing Math Activities at Home. On average, parents highly endorsed the importance of children doing math at home (Mean $=4.51, \mathrm{SD}=.77$ ). Eighty-six percent gave scores of 4 or 5 suggesting that 
parents considered doing math at home important (or very important); only 14\% considered doing math at home as somewhat or not important (scores of 2 or 3 ).

3.1.2. Beliefs about How Children Learn Math. We asked parents about the best ways to help their children learn math. Most parents reported engaging children's interest (73\%) and skills inculcation $(77 \%)$ as the best way to help their children learn math. About half (56\%) mentioned involvement in daily living activities.

3.1.3. Parents' Role in Their Children's Math Learning. As noted below, parents generally reported being actively involved in their children's math learning.

Role Models. There was variability in how often children reportedly observed their parents do math activities. Although about half the parents (48\%) reported that their children observed them engage in math activities every day or almost every day, $29 \%$ of the children observed their parents do math activities less than once a week (Mean $=3.10, \mathrm{SD}=1.03)$. Of those children who did observe their parents engage in math activities, they typically observed them participate in daily living activities, such as cooking, paying bills and bank-related matters, and going food shopping.

Provide Artifacts. Seventy-four percent of the parents said they provided their children with math artifacts. Artifacts included various math books or workbooks, games, and calendars.

Active Involvement. Almost all parents reported that it was important to assist their children with math. Eighty-six percent gave ratings of 4 or 5 to this question; $12 \%$ gave ratings of $3($ Mean $=4.53, \mathrm{SD}=.77)$.

3.1.4. Parents' Own Math Skills. Almost half of the parents $(46.5 \%)$ considered themselves good or very good at math (scores of 4 or 5); a similar percentage rated themselves as "ok" (score of 3), (Mean $=3.55, \mathrm{SD}=0.99$ ). Similarly, almost half the parents rated themselves as enjoying math (scores of 4 or 5 ) and about a third (38.4\%) reported only enjoying math somewhat (score of 3$)$ (Mean $=3.41, \mathrm{SD}=$ 1.15). Parents' rating of their enjoyment of math was strongly correlated with their ratings of how good at math they were, $r(70)=.63, p=.001$.

3.1.5. Confluence of Parents' Beliefs. Parents have a set of beliefs about how children develop and their role in such development. Therefore it is important to consider interrelations among the different types of beliefs. All of the correlational analyses controlled for maternal level of education.

Parents who emphasized the importance of children doing math at home endorsed the importance of helping their children with math, $r(70)=.54, p=.001$. Parents who emphasized children's engagement in learning reported providing artifacts, $r(67)=.44, p=.001$.

Parents who emphasized the importance of daily living activities for their children's learning also reported that their children more frequently saw them do math, $r(70)=.34$, $p=.003$, emphasized the importance of helping their children with math, $r(70)=.24, p=.045$, and gave higher ratings to enjoying math (borderline significance), $r(70)=$ $.23, p=.056$.

Parents who endorsed a skill's orientation also endorsed the importance of their children doing math at home, $r(67)=.29, p=.017$ and helping their children with math, $r(67)=.33, p=.006$. There was a negative relation between endorsing a skill's orientation and how good at math parents reported they were, $r(67)=-.26, p=.033$, and a borderline negative relation between a skill's orientation and how much parents enjoyed math, $r(67)=-.22, p=.073$.

3.2. Parents' Beliefs about Math Development, by Children's Age Group. A series of analyses of covariance (ANCOVAs) and logistic regressions were conducted to compare the four categories of parents' beliefs (the importance of children doing math activities at home, how children learn, parents' role in their children's math learning, and parents' own math skills) between parents of younger and older children. ANCOVAs were conducted when the dependent measures were rating scales and logistic regressions were used with binary outcomes. All analyses included mothers' educational level as a control variable.

As Table 2 indicates none of the analyses were statistically significant suggesting that parents of children in prekindergarten through early elementary school have similar beliefs about how children learn math and their role in such learning.

3.3. Chinese and Caucasian Parents' Beliefs about Children's Math Development. Percentages included in this section are unadjusted; ANCOVAS and logistic regression analyses include mothers' educational level as a control variable. Therefore, all reported means are adjusted for mothers' educational level. Table 3 reports coefficients and analyses for comparisons between Chinese and Caucasian parents' beliefs.

3.3.1. Importance of Children Doing Math Activities at Home. Approximately $79 \%$ of Chinese parents and $88 \%$ of Caucasian parents reported that doing math activities at home was important or very important. Although both Chinese and Caucasian parents emphasized the importance of children doing math activities, Chinese parents (Mean = $4.19, \mathrm{SE}=.16$ ) gave significantly lower ratings than Caucasian parents, $($ Mean $=4.72, \mathrm{SE}=.16)$.

3.3.2. Beliefs about How Children Learn Math. There were no statistically significant differences between Chinese and Caucasian parents in the endorsement of engaging their children's interest, Wald $\chi^{2}(N=73,1)=0.47, p=.495$, involvement in daily living activities Wald $\chi^{2}(N=73,1)=$ $0.21, p=.648$ and skills inculcation as the best way to 
TABLE 2: Beliefs of parents by age group of children.

\begin{tabular}{|c|c|c|c|}
\hline & $B$ & Statistical test & $P$ \\
\hline Importance of children doing math at home ${ }^{1}$ & 0.09 & $F(1,70)=0.23$ & .632 \\
\hline \multicolumn{4}{|l|}{ Beliefs about how children learn math ${ }^{2}$} \\
\hline Engagement & 1.13 & Wald $\chi^{2}(N=73,1)=0.05$ & .818 \\
\hline Skills & 2.13 & Wald $\chi^{2}(N=73,1)=1.52$ & .218 \\
\hline Daily living & 0.76 & Wald $\chi^{2}(N=73,1)=0.32$ & .572 \\
\hline \multicolumn{4}{|l|}{ Parents' role in their children's math learning } \\
\hline Role models ${ }^{1}$ & -0.08 & $F(1,70)=0.10$ & .750 \\
\hline Provide artifacts ${ }^{2}$ & 1.26 & Wald $\chi^{2}(N=73,1)=0.21$ & 649 \\
\hline Active involvement ${ }^{1}$ & 0.27 & $F(1,70)=2.44$ & .122 \\
\hline \multicolumn{4}{|l|}{ Parents' own math skills ${ }^{1}$} \\
\hline How good parents are at math & 0.11 & $F(1,70)=0.23$ & 634 \\
\hline How much parents enjoy math & 0.09 & $F(1,70)=0.10$ & .756 \\
\hline
\end{tabular}

Note. Parents' highest level of education was used as a covariate in all analyses. There were 40 parents of younger and 33 parents of older children included in analyses.

${ }^{1}$ ANCOVA parameter estimates reported for comparisons between groups.

${ }^{2}$ Logistic regression odds ratios reported for group predicting endorsement of each belief.

TABLE 3: Statistical analyses for chinese and caucasian parents' beliefs about children's math development.

\begin{tabular}{|c|c|c|c|}
\hline & $B$ & Statistical test & $P$ \\
\hline Importance of children doing math at home ${ }^{1}$ & 0.52 & $F(1,51)=5.06$ & .029 \\
\hline \multicolumn{4}{|l|}{ Beliefs about how children learn math ${ }^{2}$} \\
\hline Engagement & 1.58 & Wald $\chi^{2}(N=54,1)=0.47$ & .495 \\
\hline Skills & 2.74 & Wald $\chi^{2}(N=54,1)=2.12$ & .146 \\
\hline Daily living & 0.76 & Wald $\chi^{2}(N=54,1)=0.21$ & .648 \\
\hline \multicolumn{4}{|l|}{ Parents' role in their children's math learning } \\
\hline Role models ${ }^{1}$ & 0.64 & $F(1,51)=5.77$ & .020 \\
\hline Provide artifacts ${ }^{2}$ & 2.56 & Wald $\chi^{2}(N=54,1)=2.16$ & .142 \\
\hline Active involvement ${ }^{1}$ & -0.12 & $F(1,51)=0.24$ & .625 \\
\hline \multicolumn{4}{|l|}{ Parents' own math skills ${ }^{1}$} \\
\hline How good parents are at math & 0.18 & $F(1,51)=0.49$ & .487 \\
\hline How much parents enjoy math & 0.20 & $F(1,51)=0.39$ & .533 \\
\hline
\end{tabular}

Note. Parents' highest level of education was used as a covariate in all analyses. There were 28 Chinese and 26 Caucasian parents included in analyses.

${ }^{1}$ ANCOVA parameter estimates reported for comparisons between groups.

${ }^{2}$ Logistic regression odds Ratios reported for group predicting endorsement of each belief.

help their children learn math Wald $\chi^{2}(N=73,1)=2.12$, $p=.146$. On average, parents regardless of ethnicity/race endorsed these orientations.

\subsubsection{Parents' Role in Their Children's Math Learning}

Role Models. Caucasian parents (Mean $=3.46, \mathrm{SE}=.19)$ were significantly more likely than Chinese parents (Mean = $2.82, \mathrm{SE}=.18)$ to report that their children saw them engage in math activities, $F(1,51)=5.77, p=.02$, partial eta squared $=.10$.

Provide Artifacts. Differences between Chinese and Caucasian parents in providing artifacts to their children were not statistically significant, Wald $\chi^{2}(N=73,1)=2.16$, $p=.142$.

Active Involvement. There were no statistically significant differences in how strongly Chinese $($ Mean $=4.47, \mathrm{SE}=.17)$ and Caucasian parents (Mean $=4.35, \mathrm{SE}=.17$ ) rated the importance of assisting their children with math at home, $F(1,51)=.24, p=.625$, partial eta squared $=.005$.

3.3.4. Parents' Own Math Skills. There were no significant differences in how good Chinese $($ Mean $=3.43, \mathrm{SE}=.17$ ) and Caucasian (Mean $=3.61, \mathrm{SE}=.16$ ) parents believed they were in math, $F(1,51)=0.49, p=.487$, partial eta squared $=.01$. There also were no significant differences in how much Chinese $($ Mean $=3.25, \mathrm{SE}=.22)$ and Caucasian parents (Mean $=3.49, \mathrm{SE}=.22$ ) reported enjoying math, $F(1,51)=0.39, p=.533$, partial eta squared $=.008$.

3.4. Frequency of Children's Engagement in Math Activities. As Table 4 indicates, on average, parents' reported that their children engaged in math activities between several times a week and almost every day $($ Mean $=2.49 ; \mathrm{SD}=.60$ ) based on an overall measure of math activities. About half 
TABLE 4: Mean frequency of children's math activities by age group.

\begin{tabular}{|c|c|c|c|c|}
\hline & $\begin{array}{l}\text { Overall } \\
N=73\end{array}$ & $\begin{array}{l}\text { Younger } \\
N=40\end{array}$ & $\begin{array}{c}\text { Older } \\
N=33\end{array}$ & $P$ \\
\hline \multicolumn{5}{|c|}{ Composite math activities } \\
\hline Overall indicator & 2.49 & 2.57 & 2.40 & .222 \\
\hline $\begin{array}{l}\text { Average based on specific } \\
\text { math activities }\end{array}$ & 1.48 & 1.42 & 1.55 & .138 \\
\hline \multicolumn{5}{|c|}{ Specific math activities } \\
\hline Count objects & 2.42 & 2.72 & 2.07 & $<.001$ \\
\hline $\begin{array}{l}\text { Answer/ask questions "How } \\
\text { many are things are there?" }\end{array}$ & 2.21 & 2.31 & 2.08 & .324 \\
\hline Write numbers & 2.18 & 1.99 & 2.42 & .047 \\
\hline Use TV remote & 2.07 & 1.87 & 2.31 & .088 \\
\hline Add/subtract objects & 2.01 & 1.68 & 2.41 & $<.001$ \\
\hline Match/identify shapes & 2.01 & 2.38 & 1.57 & $<.001$ \\
\hline Tell time on a clock & 1.86 & 1.59 & 2.20 & .021 \\
\hline $\begin{array}{l}\text { Play with blocks/construction } \\
\text { toys }\end{array}$ & 1.73 & 1.87 & 1.56 & .210 \\
\hline Use a computer & 1.73 & 1.38 & 2.15 & .003 \\
\hline $\begin{array}{l}\text { Make patterns with } \\
\text { beads/blocks }\end{array}$ & 1.50 & 1.61 & 1.39 & .356 \\
\hline Play with money & 1.49 & 1.50 & 1.48 & .924 \\
\hline Play with puzzles & 1.42 & 1.73 & 1.05 & .001 \\
\hline Do math homework & 1.41 & 0.82 & 2.12 & $<.001$ \\
\hline Put objects in order & 1.38 & 1.51 & 1.24 & .260 \\
\hline Use math workbooks & 1.36 & 1.01 & 1.78 & .001 \\
\hline Dial telephone & 1.33 & 1.40 & 1.25 & .568 \\
\hline Play math games/board games & 1.29 & 1.21 & 1.39 & .374 \\
\hline Play video games & 1.26 & 0.79 & 1.83 & $<.001$ \\
\hline Use calendars & 1.25 & 0.82 & 1.77 & $<.001$ \\
\hline Play card games & 1.22 & 1.22 & 1.21 & .964 \\
\hline Measure things & 1.18 & 1.08 & 1.29 & .344 \\
\hline Watch math TV programs & 1.18 & 1.48 & 0.81 & .008 \\
\hline Keep score in games & 1.15 & 0.92 & 1.43 & .042 \\
\hline Look at math books & 1.12 & 1.19 & 1.05 & .583 \\
\hline $\begin{array}{l}\text { Jump rope/play hop scotch } \\
\text { games }\end{array}$ & 1.00 & 0.97 & 1.04 & .762 \\
\hline Use math flashcards & 0.69 & 0.74 & 0.63 & .632 \\
\hline Use maps & 0.42 & 0.35 & 0.52 & .314 \\
\hline
\end{tabular}

Note. Younger group includes children going into prekindergarten and kindergarten; the older group includes children going into first grade and above. Means for younger and older age group are adjusted for mothers' educational level. Overall means are not adjusted. Significance is based on results of an ANCOVA, controlling for mothers' education level.

of parents reported that their children participated in math activities every day or almost every day.

In contrast to parents' reports of the frequency of overall math activity, when we averaged the frequency of involvement across specific math activities, parents reported lower levels of children engagement (between less than once a week and one to several times a week; Mean $=1.48 ; \mathrm{SD}=$ .39). Very few (about $1.5 \%$ ) of the children reportedly engaged in math activities every day. As is apparent from the two means, parents' estimates of the frequency of their children's overall engagement in math activities was significantly higher than the average of reported engagement in specific activities, $t(72)=15.46, p=.001$. Results presented in the following sections are based on the average of the specific math activities composite rather than the overall composite question because we think it is a more accurate reflection of children's frequency of engagement.

Table 4 shows important variability in the level of children's reported engagement across math activities. The most commonly occurring activities (mean of 2.00 or higher, once to several times a week) are counting objects, asking/answering questions about quantity, using the television remote, and writing numbers. Lowest levels of reported engagement are found for playing board or card games or watching math video games.

3.5. Younger and Older Children's Reported Engagement in Math Activities. There were some significant differences between children in the two age groups in the frequency of engagement in specific activities (see Table 4). As expected, younger children were more likely to be involved than older children in basic math activities. The specific activities that younger children more frequently reportedly did were count objects, $F(1,70)=13.34, p=$ .001 , partial eta squared $=.168$; match or identify shapes, $F(1,70)=14.13, p=.001$, partial eta squared $=.168$; play with puzzles, $F(1,70)=12.01, p=.001$, partial eta squared $=.147$; and watch math television programs, $F(1,70)=7.43, p=.008$, partial eta squared $=.096$. In contrast, older children significantly more frequently engaged in activities such as add/subtract things, $F(1,70)=$ $14.64, p=.001$, partial eta squared $=.173$; write numbers $F(1,70)=4.09, p=.047$, partial eta squared $=$ .058 , do homework (assigned by teachers), $F(1,70)=24.33$, $p=.001$, partial eta squared $=.266$; use math workbooks, $F(1,70)=12.03, p=.001$, partial eta squared $=.149$ keep score in games, $F(1,70)=4.27, p=.042$, partial eta squared $=.057$; use calendars, $F(1,70)=13.52, p=.001$, partial eta squared $=.162$; tell time, $F(1,70)=5.61, p=$ .021 , partial eta squared $=.074$; play video games, $F(1,70)=$ $19.22, p=.001$, partial eta squared $=.215$; use a computer, $F(1,670)=9.72, p=.003$, partial eta squared $=.122$.

3.6. Chinese and Caucasian Children's Reported Frequency of Engagement in Math Activities. There were significant differences between Chinese and Caucasian children's reported frequency of engagement for some math activities (see Table 5). Caucasian children reportedly engaged more frequently in the following math-related activities: counting objects, $F(1,51)=4.43, p=.040$, partial eta squared $=.080$; playing with or using money, $F(1,51)=10.27, p=.002$, partial eta squared $=.168$; matching or identifying shapes, $F(1,51)=4.27, p=.044$, partial eta squared $=.077$; ordering objects, $F(1,51)=6.01, p=.018$, partial eta squared $=.105$; measuring things, $F(1,51)=7.81, p=$ .007 , partial eta squared $=.133$; playing math games/board games, $F(1,51)=4.76, p=.034$, partial eta squared $=.085$; keeping score in games, $F(1,51)=9.59, p=.003$, partial eta squared $=.158$. 
TABle 5: Mean frequency of children's math activities.

\begin{tabular}{|c|c|c|c|c|}
\hline & $\begin{array}{l}\text { Overall } \\
N=73\end{array}$ & $\begin{array}{l}\text { Chinese } \\
N=28\end{array}$ & $\begin{array}{c}\text { Caucasian } \\
N=26\end{array}$ & $P$ \\
\hline \multicolumn{5}{|c|}{ Composite math activities } \\
\hline Overall indicator & 2.49 & 2.41 & 2.64 & .154 \\
\hline $\begin{array}{l}\text { Average based on specific } \\
\text { math activities }\end{array}$ & 1.48 & 1.34 & 1.53 & .091 \\
\hline \multicolumn{5}{|c|}{ Specific math activities } \\
\hline Count objects & 2.42 & 2.10 & 2.58 & .040 \\
\hline $\begin{array}{l}\text { Answer/ask questions } \\
\text { "How many are things are } \\
\text { there?" }\end{array}$ & 2.21 & 2.16 & 2.02 & .628 \\
\hline Write numbers & 2.18 & 2.48 & 2.00 & .057 \\
\hline Use TV remote & 2.07 & 1.83 & 2.03 & .551 \\
\hline Add/subtract objects & 2.01 & 1.91 & 2.22 & .215 \\
\hline Match/identify shapes & 2.01 & 1.73 & 2.30 & .044 \\
\hline Tell time on a clock & 1.86 & 1.63 & 1.78 & .655 \\
\hline $\begin{array}{l}\text { Play with } \\
\text { blocks/construction toys }\end{array}$ & 1.73 & 1.65 & 1.95 & .288 \\
\hline Use a computer & 1.73 & 1.90 & 1.76 & .669 \\
\hline $\begin{array}{l}\text { Make patterns with } \\
\text { beads/blocks }\end{array}$ & 1.50 & 1.38 & 1.52 & .634 \\
\hline Play with money & 1.49 & 0.95 & 1.86 & .002 \\
\hline Play with puzzles & 1.42 & 1.46 & 1.20 & .239 \\
\hline Do math homework & 1.41 & 1.27 & 1.64 & .309 \\
\hline Put objects in order & 1.38 & 1.00 & 1.62 & .018 \\
\hline Use math workbooks & 1.36 & 1.54 & 1.04 & .082 \\
\hline Dial telephone & 1.33 & 1.16 & 0.98 & .507 \\
\hline $\begin{array}{l}\text { Play math games/board } \\
\text { games }\end{array}$ & 1.29 & 1.16 & 1.64 & .034 \\
\hline Play video games & 1.26 & 1.30 & 1.26 & .911 \\
\hline Use calendars & 1.25 & 1.09 & 1.40 & .374 \\
\hline Play card games & 1.22 & 1.08 & 1.45 & .127 \\
\hline Measure things & 1.18 & 0.73 & 1.41 & .007 \\
\hline Watch math TV programs & 1.18 & 1.01 & 0.99 & .937 \\
\hline Keep score in games & 1.15 & 0.68 & 1.54 & .003 \\
\hline Look at math books & 1.12 & 1.13 & 0.90 & .424 \\
\hline $\begin{array}{l}\text { Jump rope/play hop scotch } \\
\text { games }\end{array}$ & 1.00 & 0.89 & 0.89 & .991 \\
\hline Use math flashcards & 0.69 & 0.51 & 0.75 & .373 \\
\hline Use maps & 0.42 & 0.44 & 0.60 & .481 \\
\hline
\end{tabular}

Note. Means for Chinese and Caucasian parents are adjusted for mothers' educational level. Overall means are not adjusted. Overall means represent means for all ethnic/racial groups.

Chinese children reportedly engaged more frequently (borderline effects) in writing numbers, $F(1,51)=3.80$, $p=.057$, partial eta squared $=.071$, and using workbooks, $F(1,51)=3.15, p=.082$, partial eta squared $=.058$.

3.7. Associations between Parents' Beliefs and Frequency of Children's Math Activities. We first calculated partial correlations between parents' beliefs and children's math activities to determine which beliefs to include in a regression
TABLE 6: Summary of multiple regression analysis for parent beliefs predicting frequency of math activities at home.

\begin{tabular}{|c|c|c|c|c|c|}
\hline Variable & $B$ & $\mathrm{SE}(B)$ & $\beta$ & $t$ & $P$ \\
\hline Intercept & 0.67 & 0.27 & & 2.46 & .016 \\
\hline Mothers' education level & -0.04 & 0.02 & -.16 & -1.54 & .135 \\
\hline $\begin{array}{l}\text { Importance of children } \\
\text { doing math at home }\end{array}$ & 0.13 & 0.06 & .25 & 2.35 & .022 \\
\hline Parents' role_role models & 0.10 & 0.04 & .26 & 2.28 & .026 \\
\hline $\begin{array}{l}\text { How children learn } \\
\text { math-daily living }\end{array}$ & 0.16 & 0.09 & .21 & 1.82 & .073 \\
\hline
\end{tabular}

Note. $R^{2}=.262, F(4,68)=6.05, P<.001$.

model. Given the small sample size, it was important to limit the number of predictors in the regression models. Accordingly, we included only those predictors that were significantly correlated with frequency of children's math activities. Correlation and regression analyses controlled for mothers' educational level.

The frequency of children's math activities (composite measure based on average of specific math activities) was significantly related to three parent beliefs: the importance of children doing math activities at home, $r(70)=.35$, $p=.003$; the importance of involving children in daily living activities, $r(70)=.34, p=.003$; the frequency with which they saw their parents do math activities (parents as role models), $r(70)=.38, p=.001$. On average, children of parents who consider it important to have their children do math activities at home, see themselves as role models, and involve children in daily living math activities are more frequently involved in math activates at home.

It is noteworthy that neither parents' enjoyment of math nor how good they are at math was significantly related to the frequency with which children did math at home, $r(70)=.15, .18, p=.21, .14$, respectively. Skills inculcation for helping their children learn math was not significantly related to the frequency with which children participated in math activities at home, $r(70)=.001, p=.993$.

Table 6 shows the regression analysis with parents' beliefs as predictors and the composite measure of engagement in math activities as the dependent variable. Parents' ratings of the importance of children doing math at home, and parents' ratings of the frequency with which their child sees them do math activities were both significantly related to the frequency with which children reportedly did math at home. Parents' endorsement of involving their children in daily living activities as a means of learning math showed a borderline relation with children's engagement in math activities. These results show the importance of parents' beliefs for increasing the frequency of children's engagement in math activities.

\section{Discussion}

Far too many children in the United States do not become competent in math [1]. This exploratory study examined the math home-environment of children by analyzing parents' beliefs and children's involvement in math activities. Given the strong connection between children's involvement in 
math activities at home and their math learning $[8,10,11]$, we wanted to provide some insights into the basis of the variability in children's home-based involvement in math activities. Understanding the reason for the variability in the frequency with which children participate in math activities at home is an important first step towards neutralizing the math disadvantages experienced by a significant number of children.

Five important findings emerged from this study: the association between parents' beliefs about children's math development and the frequency of children's engagement in math activities at home, the relation among parents' beliefs about children's math development, the frequency and nature of children's math activities, age-related patterns in children's engagement in math activities, and comparisons between Chinese and Caucasian parents' beliefs and children's math activities.

One, these results highlight the importance of considering parents' beliefs in any model of children's math development [19]. The frequency with which children reportedly participated in math activities was related to the frequency with which children observed their parents do math activities [29]. It also was related to parents' beliefs about using daily living activities to foster math learning, and to parents' beliefs about the importance of children doing math at home.

There is an interesting difference between parents' beliefs about math, as documented in this study, and reading development, as documented in Serpell et al. [23]. In contrast to Serpell et al.'s [23] findings, where the importance of using daily living activities to help their children learn to read was not mentioned, more than half of the parents in this study mentioned that involvement in daily living activities is an important means of fostering children's math development. The difference in patterns between reading and math underscores the need to more fully investigate children's home-math environments. We cannot just assume that how parents foster their children's reading competencies will apply to how they foster math competencies.

Two, this study demonstrates the importance of considering the relations among different dimensions of parents' beliefs. We considered four sets of parental beliefs: the importance of children doing math activities at home, how children learn math (through engaging child's interest, inculcating skills, and using daily living activities), parents' role in their children's math learning (serve as role models of engagement, provide artifacts, and active involvement in children's math learning), and parents' own math skills (selfrated skills and enjoyment). By considering different aspects of parents' beliefs, we were able to document relations among the beliefs. Such documentation is necessary to obtain a more valid understanding of parents' beliefs about children's math development. Only with a valid understanding will we be able to design interventions that are effective for a diverse population of children.

Note that parents' enjoyment of math and their selfrated ability in math were not significant predictors of the frequency with which children engaged in math activities. The lack of association between mothers' perceptions of their own ability and enjoyment and children's math engagement may reflect the simplicity of math activities that children, on average, are involved in at this age. As children become involved with more complicated math activities, these particular beliefs may become relevant.

Consider the associations among the beliefs held by parents. Parents who emphasized the importance of children doing math at home also emphasized the importance of helping their child with math, and, in particular, that parents teach their children math. Parents who emphasized the importance of daily living activities for their child's learning also reported that their child more frequently saw them do math. Parents who emphasized the importance of helping their children with math tended to report that they enjoyed math.

Three, this study confirmed the variability and relatively limited participation of children in math activities at home [15]. About 44\% reported mean engagement in math activities (based on the average of activities) between once and several times a week. About 53\% reported less frequent engagement in math activities. Although we do not know what is the minimum involvement needed to acquire or improve math skills, we suspect that the limited participation reported by the children in this study is not optimal.

Four, these results also add to the literature by showing age-related differences in children's reported engagement in math activities. Differences between younger and older children in the frequency of reported engagement were found in specific activities. Not surprisingly, younger children were more likely to reportedly engage in activities likely to foster counting and basic math skills; older children reportedly engaged in activities that fostered more advanced skills (addition and subtraction) and/or required more advanced competencies (using calendars and playing video games). However, parents' beliefs about how to foster math were not sensitive to the differences in the two age groups of children. It is possible that differences would have emerged if we had used a wider age span. Alternatively, the beliefs tapped in this study may be stable and not subject to change as children go from prekindergarten to elementary school.

Five, these findings also add to the body of research on Chinese and Caucasian children's math development. In contrast to previous findings [44]; (Li [45]), Chinese and Caucasian parents in this study showed somewhat similar beliefs about how children's developed math. When there were differences between groups, Caucasian parents reported higher frequency of being role models for their children and placed more emphasis on the importance of their children doing math at home.

We propose five possible explanations for these findings with Chinese and Caucasian parents in this study. The first three explanations focus on changing acculturation patterns. The next two focus on potential limitations of what was explored in this study. First, Chinese immigrants in this study mainly lived in the suburbs and did not benefit from living in strong ethnic enclaves (and sources of educational support) unlike other Chinese immigrants in the United States who are more likely to live in cities [46]. Consistent with the first option, the Chinese parents included in this study may be more culturally assimilated 
to the Caucasian mainstream culture than were previous generations of Chinese immigrants or those who participated in other studies. Third, given globalization trends, it may be possible that the beliefs and practices of parents from different countries are becoming more homogenous over time. Fourth, Chinese and Caucasian parents may differ on other pertinent beliefs not explored in this study. For example, we did not explore parents' expectations for children's academic accomplishments and progress, areas of documented differences across ethnic/racial groups [39]. Fifth, differences in Chinese and Caucasian children's math skills may be due to factors other than parents' beliefs. Further empirical analyses should be conducted to study the relative importance of these explanations.

4.1. Limitations and Future Directions. Because the sample size in this study, particularly for African Americans and Latinos, was fairly small, the findings are exploratory in nature. Future studies should use a larger sample to capture a more representative portrait of the math homeenvironments of children from diverse ethnic/racial backgrounds. The important variability in ethnic/racial/income patterns of math development $[7,47,48]$ highlights the need to examine group-specific family environments. The nature of this study limited any such exploration to only Chinese and Caucasian families residing in the mid-Atlantic region of the United States.

The theoretical model guiding this research is that parents' beliefs are related to children's activities which, in turn, are related to children's math skills. However, we were unable to include a measure of children's math skills in this study. We expect that children's math activities are related to children's math skills (e.g., $[8,10,11])$. Nevertheless, future research should investigate the full model. It is also important to note that our measures of children's math activities are based on parents' reports. Future research should attempt to confirm these findings with some form of direct measure or with corroboration, if possible, with reports by children.

This study investigated a small portion of children's home environments and parents' math-related beliefs and practices. Although such a directed focus appears to us to be valid, it is important for future research to compare parents' beliefs and practices across different academic and nonacademic domains to get a fuller picture of home learning opportunities available to different groups of children.

Regardless of the limitations of this study, our analysis provides new exploratory evidence of the importance of understanding children's math home-environments. These exploratory findings can inform the development of homebased interventions to improve math outcomes of children from different ethnic/racial groups. For example, these results show that certain beliefs of parents, but not others, predicted children's engagement in math activities. Educating parents about the importance of having their children engage in math activities at home, serving as role models of such engagement, and using appropriate daily living activities involving math are important avenues for facilitating children's increased engagement with math at home. Recall that only about half the parents (56\%) mentioned involvement in daily living activities as a way to facilitate children's math development. Clearly, some parents are not aware of the positive implications of involving their children in frequent math-related activities. Parents can also be encouraged to give increased attention to being role models of engagement for their children. Only about half (49\%) the parents reported that their children saw them do math activities every day and $10 \%$ noted their children never saw them engaged in math activities. In fact, taking advantage of the many daily living activities that involve math (e.g., cooking and paying bills) may be an excellent way for parents to serve as role models of math engagement for their children. In contrast, neither parents' own enjoyment of math nor their self-rated skills predicted whether this age group of children engaged in math at home.

\section{Conclusion}

This study documented aspects of children's home math environments to explore the relation between parents' beliefs and children's participation in math activities. Although research shows that children's math activities at home are related to their math skills, a significant portion of children have limited math involvement at home [8, 10, 11, 15]. Parents' beliefs about children's math development and their role in fostering such development was significantly related to children's math activities. Although further research is needed to confirm the findings with a larger sample, particularly for analyses focusing on ethnic/racial comparisons, and to include measures of children's math competencies, these findings are an important first step that will aid in the development of home-based interventions to facilitate children's math skills.

\section{Acknowledgments}

The authors would like to thank Jared Au Yeung, Shelter Bamu, Sumit Bose, Felix Burgos, Brittany Cholakian, Vishka Correya, Semone Dupigny, Rebecca Gao, Jennifer Gibbs, Christine Glancey, Dan Li, Claudia Paiva, Kishan Patel, Samantha Schene, Alexandria Spaay, Kirsten Spence, Mariana Triantos, Judy Wang, Kaitlyn Wilson, and Zuotang Zhang for their assistance. This research was supported by UMBC Venture SEED funds and MIPAR.

\section{References}

[1] National Research Council and Committee on Early childhood Mathematics, Mathematics Learning in Early Childhood: Paths Towards Excellence and Equity, Center for Education, Division of Behavioral and Social Sciences and Education, The National Academies Press, Washington, DC, USA, 2009.

[2] S. Baldi, Y. Jin, M. Skemer, P. J. Green, and D. Herget, Highlights From PISA 2006: Performance of U.S. 15-YearOld Students in Science and Mathematics Literacy in an International Context (NCES 2008-016), National Center for Education Statistics, Institute of Education Sciences, U.S. Department of Education, Washington, DC, USA, 2007.

[3] I. V. S. Mullis, M. O. Martin, P. Foy et al., "Findings from IEA's Trends in International Mathematics and Science Study 
at the fourth and eighth grades," TIMSS 2007 International Mathematics Report, TIMSS \& PIRLS International Study Center, Boston College, Chestnut Hill, MA, USA, 2008.

[4] M. Burchinal, K. McCartney, L. Steinberg et al., "Examining the Black-White achievement gap among low-income children using the NICHD study of early child care and youth development," Development, vol. 82, pp. 1404-1420, 2011.

[5] R. Crosnoe, F. Morrison, M. Burchinal et al., "Instruction, teacher-student relations, and math achievement trajectories in elementary school," Journal of Educational Psychology, vol. 102, no. 2, pp. 407-417, 2010.

[6] G. J. Duncan, C. J. Dowsett, A. Claessens et al., "School readiness and later achievement," Developmental Psychology, vol. 43, no. 6, pp. 1428-1446, 2007.

[7] N. C. Jordan, D. Kaplan, C. Ramineni, and M. N. Locuniak, "Early math matters: kindergarten number competence and later mathematics outcomes," Developmental Psychology, vol. 45, no. 3, pp. 850-867, 2009.

[8] Y. Anders, H.-G. Rossbach, S. Weinert et al., "Home and preschool learning environments and their relations to the development of early literacy skills," Early Childhood Research Quarterly, vol. 27, pp. 231-244, 2012.

[9] B. Blevins-Knabe and L. Musun-Miller, "Number use at home by children and their parents and its relationship to early mathematical performance," Infant and Child Development, vol. 5, no. 1, pp. 35-45, 1996.

[10] J.-A. LeFevre, E. Polyzoi, S. L. Skwarchuk, L. Fast, and C. Sowinski, "Do home numeracy and literacy practices of Greek and Canadian parents predict the numeracy skills of kindergarten children?” International Journal of Early Years Education, vol. 18, no. 1, pp. 55-70, 2010.

[11] J.-A. Lefevre, S.-L. Kwarchuk, B. L. Smith-Chant, L. Fast, D. Kamawar, and J. Bisanz, "Home numeracy experiences and children's math performance in the early school years," Canadian Journal of Behavioural Science, vol. 41, no. 2, pp. 5566, 2009.

[12] S.-L. Skwarchuk, "How do parents support preschoolers' numeracy learning experiences at home?" Early Childhood Education Journal, vol. 37, no. 3, pp. 189-197, 2009.

[13] E. C. Melhuish, M. B. Phan, K. Sylva, P. Sammons, I. SirajBlatchford, and B. Taggart, "Effects of the home learning environment and preschool center experience upon literacy and numeracy development in early primary school," Journal of Social Issues, vol. 64, no. 1, pp. 95-114, 2008.

[14] G. B. Ramani and R. S. Siegler, "Promoting broad and stable improvements in low-income children's numerical knowledge through playing number board games," Child Development, vol. 79, no. 2, pp. 375-394, 2008.

[15] J. R. H. Tudge and F. Doucet, "Early mathematical experiences: observing young black and white children's everyday activities," Early Childhood Research Quarterly, vol. 19, no. 1, pp. 21-39, 2004.

[16] U. Bronfenbrenner, The Ecology of Human Development, Harvard University Press, Cambridge, Mass, USA, 1979.

[17] L. S. Vygotsky, Mind in Society: The Development of Higher Psychological Proces, Harvard University Press, Cambridge, Mass, USA, 1978.

[18] C. M. Super and S. Harkness, "The developmental niche: a conceptualization at the interface of child and culture," International Journal of Behavioral Development, vol. 9, pp. 545-569, 1986.

[19] M. H. Bornstein and L. R. Cote, "Mothers' parenting cognitions in cultures of origin, acculturating culture, and cultures of destination," Child Development, vol. 75, no. 1, pp. 221-235, 2004.

[20] M. Keels, "Ethnic group differences in early head start parents' parenting beliefs and practices and links to children's early cognitive development," Early Childhood Research Quarterly, vol. 24, no. 4, pp. 381-397, 2009.

[21] I. E. Sigel, "The belief-behavior connection: a resolvable dilemma?" in Parental Belief Systems: The Psychological Consequences for Children, I. E. Sigel, A. V. McGillicuddy-DeLisi, and J. J. Goodnow, Eds., pp. 433-456, Lawrence Erlbaum Associates, Hillsdale, NJ, USA, 2nd edition, 1992.

[22] T. S. Weisner, "Ecocultural understanding of children's developmental pathways," Human Development, vol. 45, no. 4, pp. 275-281, 2002.

[23] R. Serpell, L. Baker, and S. Sonnenschein, Becoming Literate in the City: The Baltimore Early Childhood Project, Cambridge, Mass, USA, 2005.

[24] S. Sonnenschein, "Engaging children in the appropriation of literacy: the importance of parental beliefs and practices," in Contemporary Perspectives in Early Childhood Education, O. Saracho and B. Spodek, Eds., pp. 127-149, Information Age Publishing, Greenwich, CT, USA, 2002.

[25] J. J. Goodnow, “Parents' ideas, children's ideas: correspondence and divergence," in Parental Belief Systems:The Psychological Consequences for Children, I. E. Sigel, A. V. McGillicuddy-DeLisi, and J. J. Goodnow, Eds., pp. 293-317, Lawrence Erlbaum Associates, Hillsdale, NJ, USA, 2nd edition, 1992.

[26] A. V. McGillicuddy-DeLisi and I. E. Sigel, "Parental Beliefs," in Handbook of Parenting, M. H. Bornstein, Ed., vol. 3, pp. 333358, 2nd edition, 2002.

[27] J. S. Eccles, "Families, schools, and developing achievementrelated motivations and engagement," in Handbook of Socialization, J. E. Grusec and P. D. Hastings, Eds., pp. 665-691, Guilford Press, New York, NY, USA, 2007.

[28] F. J. Morrison, C. M. Connor, and H. J. Bachman, "The transition to school," in Handbook of Early Literacy, D. Dickinson and S. B. Neuman, Eds., pp. 375-394, Guildford, New York, NY, USA, 2006.

[29] S. D. Simpkins, P. E. Davis-Kean, and J. S. Eccles, "Parents' socializing behavior and children's participation in math, science, and computer out-of-school activities," Applied Developmental Science, vol. 9, pp. 14-30, 2005.

[30] S. Sonnenschein and K. Munsterman, "The influence of home-based reading interactions on 5-year-olds' reading motivations and early literacy development," Early Childhood Research Quarterly, vol. 17, no. 3, pp. 318-337, 2002.

[31] S. Sonnenschein, L. Baker, and R. Serpell, "The Early Childhood Project: a 5-year longitudinal investigation of children's literacy development in sociocultural context," in Literacy Development and Enhancement Across Orthographies and Cultures, D. Aram and O. Korat, Eds., pp. 85-96, Springer, New York, NY, USA, 2010.

[32] C. M. Super and S. Harkness, "Culture structures the environment for development," Human Development, vol. 45, no. 4, pp. 270-274, 2002.

[33] S. Harkness and C. M. Super, Parents' Cultural Belief Systems: Their Origins, Expressions, and Consequences, Guilford Press, New York, NY, USA, 1996.

[34] R. H. Bradley, "Environment and parenting," in Handbook of Parenting, M. H. Bornstein, Ed., vol. 2 of Biology and Ecology of Parenting, pp. 281-314, Lawrence Erlbaum Associates, Mahwah, NJ, USA, 2002. 
[35] D. C. Geary, L. Fan, and C. C. Bow-Thomas, "Numerical cognition: loci of ability differences comparing children from China and the United States," Psychological Science, vol. 3, pp. 180-185, 1992.

[36] H. W. Stevenson, S. Y. Lee, C. S. Chen et al., "Mathematics achievement of children in China and the United States," Child Development, vol. 61, no. 4, pp. 1053-1066, 1990.

[37] R. Chao and V. Tseng, "Parenting of Asians," in Handbook of Parenting, M. H. Bornstein, Ed., vol. 4 of Social Conditions and Applied Parenting, pp. 59-93, Lawrence Erlbaum Associates, Mahwah, NJ, USA, 2002.

[38] J. Li, S. D. Holloway, J. Bempechat, and E. Loh, "Building and using a social network: nurture for low-income Chinese American adolescents' learning," in Beyond Families and Schools: How Broader Social Contexts Shape the Adjustment of Children and Youth in Immigrant Families, H. Yoshikawa and N. Way, Eds., pp. 7-25, 2008.

[39] Y. Yamamoto and S. D. Holloway, "Parental expectations and children's academic performance in sociocultural context," Educational Psychology Review, vol. 22, no. 3, pp. 189-214, 2010.

[40] L. Okagaki and R. J. Sternberg, "Parental beliefs and children's school performance," Child Development, vol. 64, pp. 36-56, 1993.

[41] G. J. Duncan and K. A. Magnuson, "Can family socioeconomic resources account for racial and ethnic test score gaps?" The Future of Children, vol. 15, no. 1, pp. 35-54, 2005.

[42] M.-A. Suizzo and L. M. Stapleton, "Home-based parental involvement in young children's education: examining the effects of maternal education across U.S. ethnic groups," Educational Psychology, vol. 27, no. 4, pp. 533-556, 2007.

[43] R. H. Bradley and R. F. Corwyn, "Age and ethnic variations in family process mediators of SES," in Socioeconomic Status, Parenting, and Child Development, M. H. Bornstein and R. H. Bradley, Eds., pp. 151-188, Lawrence Erlbaum Associates, Mahwah, NJ, USA, 2003.

[44] R. K. Chao, "Beyond parental control and authoritarian parenting style: understanding Chinese parenting through the cultural notion of training," Child Development, vol. 65, no. 4, pp. 1111-1119, 1994.

[45] J. Li, "Chinese conceptualization of learning," Ethos, vol. 29, no. 2, pp. 111-137, 2001.

[46] M. Zhou, Contemporary Chinese American: Immigration, Ethnicity, and Community Transformation, Temple University Press, Philadelphia, Pa, USA, 2009.

[47] C. S. Huntsinger and P. E. Jose, "Parental involvement in children's schooling: different meanings in different cultures," Early Childhood Research Quarterly, vol. 24, no. 4, pp. 398410, 2009.

[48] S. F. Reardon and C. Galindo, "The hispanic-white achievement gap in math and reading in the elementary grades," American Educational Research Journal, vol. 46, no. 3, pp. 853 891, 2009. 


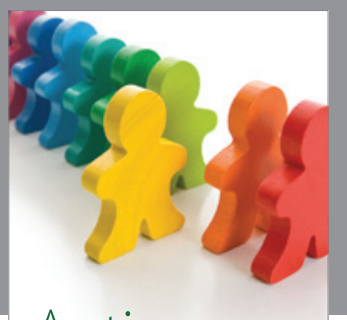

Autism

Research and Treatment
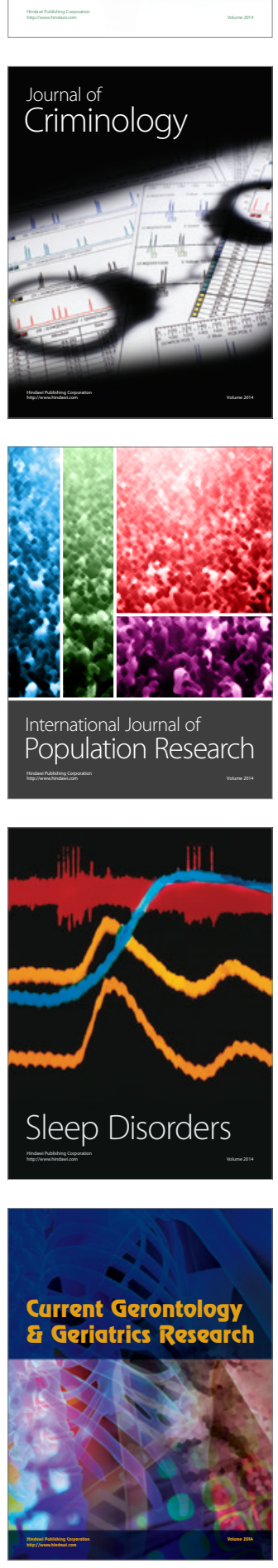
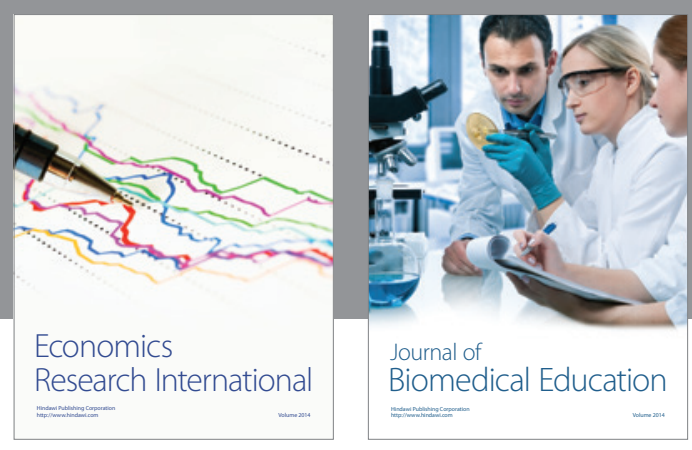

Journal of

Biomedical Education

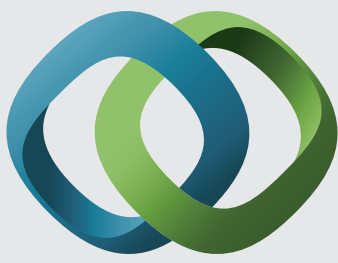

\section{Hindawi}

Submit your manuscripts at

http://www.hindawi.com
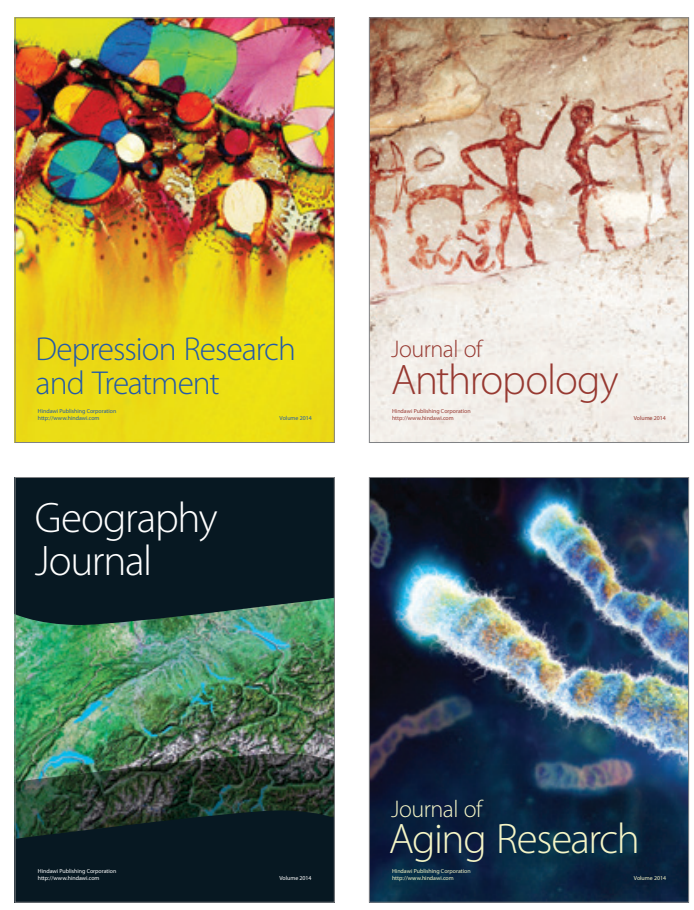

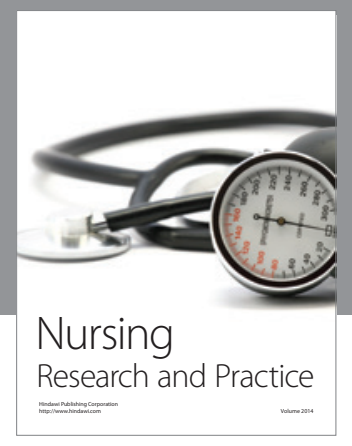

Nursing

Research and Practice

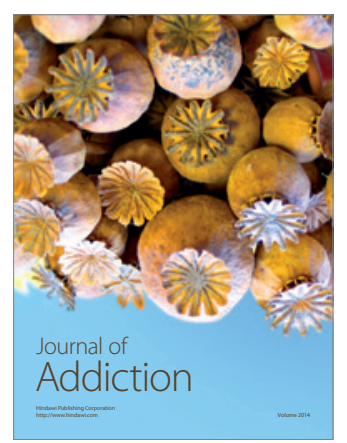

Child Development

Research

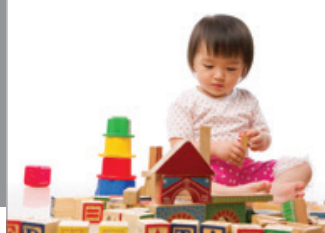

迥
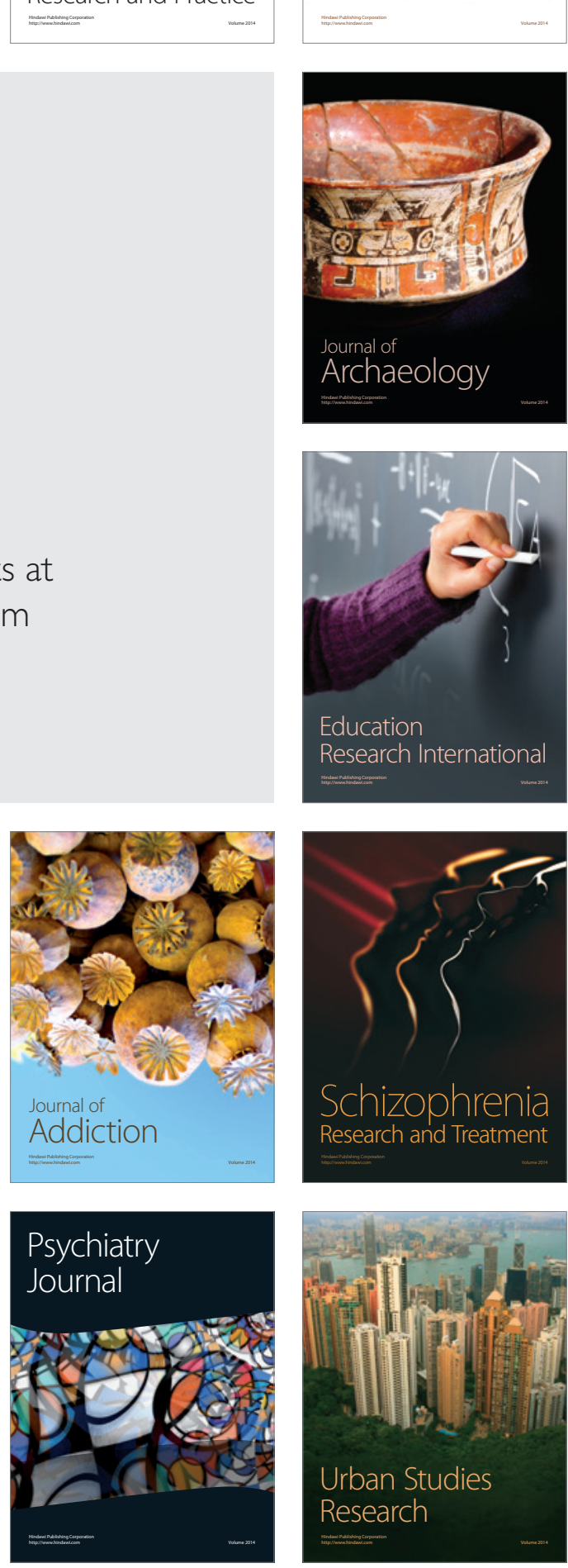